\title{
Toward Developing a Mobile Channel Extension Model: Roles of Compatibility, Subjective Norm, and Media Influences
}

\author{
Hyun-Hwa Lee ${ }^{\dagger}$ Jihyun Kim* \\ Dept. of Fashion Design \& Textiles, Inha University \\ *Dept. of Apparel, Housing, \& Resource Management, Virginia Polytechnic Institute and State University \\ Received September 30, 2011; Revised December 2, 2011; Accepted December 22, 2011
}

\begin{abstract}
The present research developed and empirically examined a theoretical model called a Mobile Channel Extension Model for consumer behavior toward mobile commerce. We proposed three antecedents: compatibility of, subjective norm regarding, and media influence regarding mobile use for communication purposes that influence the attitude toward the subjective norm and media influences of mobile use for shopping. These in turn positively influenced the consume's intention to use mobile devices for shopping. A Structural equation modeling analysis, using the data collected from a national online survey of 524 U. S. multichannel shoppers, confirmed the proposed model. The theoretical implications of these effects were discussed and managerial suggestions were made for both academicians and practitioners.
\end{abstract}

Key words: Mobile shopping, Compatibility, Subjective norm, Media influences

\section{Introduction}

The International Telecommunication Union reported that the dynamic increase of mobile phone users globally reached to over 5 billion at the end of 2010 (IANS, 2010). In 2008 there were more than 270 million wireless subscribers in the United States (Moorman, 2009). This vast mobile world provides multiple advantages not found in traditional communication channels (Tsang et al., 2004). While there have been numerous applications and research performed on the use of mobile services in other regions like East Asia and Europe (Cheong \& Park, 2005; Li \& McQueen, 2008; Murphy, 2007), it remains apparent that mobile service usage in the U.S. follows the trends in other countries (Lee \& Lee, 2007). Yet, the increase in mobile transactions and sales is credited to the easy access to marketing information that mobile devices provide to customers containing information about different products to assist in their decision making at

\footnotetext{
${ }^{\dagger}$ Corresponding author

E-mail: hyunhwa@inha.ac.kr
}

the point of purchase (Constantiou et al., 2006; Mort \& Drennan, 2002; Vollmer, 2008; Wei et al., 2010). Thus, the potential of the mobile channel as a shopping medium in a multichannel retailing environment would be important to most national chain retailers operating brick-and-mortar and online stores. Multichannel shoppers have particularly shown positive attitudes toward promotion methods from multichannel retailers (Pentina \& Hasty, 2009) and are satisfied with and/or are loyal to the retailers (Frattaroli, 2009; Lee \& Kim, 2010; Rangaswamy \& Van Bruggen, 2005; Shankar \& Winer, 2005). They would, therefore, be an appropriate consumer group to examine potential for the use of mobile devices for shopping as an extension from the current multiple retail channels.

According to media dependency theory (Ball-Rokeach \& DeFleur, 1976), individuals who become more dependent on a certain type of media to meet particular needs, such as information and entertainment, are more likely to consider the medium to be of great importance to them. Furthermore, Lee and Lee (2010) examined channel extension behaviors between Internet and 
mobile and found that current use of Internet services influences future intention to use the same services via mobile. Therefore, our motivation to conduct the present study was to examine the consumer's attitude as well as perception shift from mobile device usage for communication to that for shopping purposes using the framework of media dependency theory (Ball-Rokeach \& DeFleur, 1976; Grant et al., 1991). Since U.S. mobile marketing is in an infant stage, it would be meaningful to investigate general U.S. consumers' attitudes and perceptions regarding the use of mobile devices for communication purposes, and further to predict their behavioral intentions in regard to utilizing the mobile device for shopping purposes. Considering the fact that mobile shopping is considered innovative by the general consumer, the effects of media such as newspaper and popular press on consumers' attitudes would be significant, as previous studies have asserted the role that mass media has in increasing consumers' awareness about new technology and ideas in the earlier stages of product life cycle or diffusion cycle (Bhattacherjee, 2000; Shao, 1999). However, little is known about this media effect on behavior intentions to use mobile shopping. Thus, the purpose of the present study was to investigate antecedents affecting U.S. multichannel shoppers' intention to use mobile devices for shopping by extending usages of mobile devices from a communication level to a shopping level. To examine our proposition (an individual's attitude shift regarding mobile device usage from communication to shopping) grounded on the media dependency theory, we incorporated media influences, as an external variable in both communication and shopping levels, in addition to consumer attitudes and subjective norms adopted from the theory of reason action to predict intention to use mobile shopping.

\section{Conceptual Framework and Hypotheses Development}

Media dependency theory posits that an individual's affinity for and dependency on a certain medium may lead to favorable attitudes toward purchase behaviors using that same medium. Media dependency is defined as "the overall degree to which an individual relies on a medium to fulfill personal goals" (Grant et al., 1991, p. 780). According to the media dependency theory (BallRokeach \& DeFleur, 1976), people who become more dependent on a certain media to meet specific needs, such as information and entertainment, are more likely to consider the media to be of great importance to them. For instance, individuals who heavily watch televised broadcasting programs to learn about the world and/or local news are more inclined to exhibit more positive attitude toward the televised broadcasting system in general, and in turn, positive intention to perform other activities (e.g., purchasing goods through infomercials or shopping network on TV) through that particular medium (e.g., Grant et al., 1991). In effect, the media becomes a more influential and powerful source for that individual to rely upon for many other activities, including communication and shopping. This theory has been applied to consumer behavior research to examine attitudes and/or behavioral intention shift from television watching to television shopping (Grant et al., 1991; Skumanich \& Kintsfather, 1998), from online searching to online shopping (Balabanis \& Reynolds, 2001; Kim \& Park, 2005), and from mobile communication to mobile shopping (Bigné et al., 2007; Kim et al., 2009).

As postulated in the study of Kim and Park (2005), attitude toward an offline retailer can be shifted to that toward the online version of the offline retailer. They also found that behavioral intention (searching for the product information) via the online retailer was transited to the behavioral intention toward shopping intention via the online retailer. In Kim and Park's study (2005), this transitional relationship was explained by the media dependency theory which posits the heavy usage/dependency of a certain medium would predict the user's adoption of that particular medium for further various activities. This theory was mirrored in the findings of the Kim and Park (2005) as the consumers' willingness to use the online retailer for product information search (more common activity using the medium, which is the Internet as retail channel in the study) was extended to the newer activity, online shopping via that online retailer (more advanced or extended activity regarding the innovativeness/leadership of the user/consumer).

Media dependency theory serves as an underpinning 
conceptual framework to predict the positive relationships between the use of mobile technology or device for communication purposes and that of mobile technology or device for shopping purposes. In the present study, mobile communication was operationally defined as any activities occurring through mobile devices to correspond others including mobile calls, short message services (SMS), and multimedia message services (MMS). In the following sections, we explain how different concepts from various theories help us develop our conceptual framework to understand the attitude shift in mobile device usage from communication to shopping.

\section{Compatibility in the Diffusion of Innovation Theory}

In Diffusion of Innovation, Rogers (1995) explains how and why the new ideas and/or innovative technologies spread throughout cultures by way of certain channels over time among the members of a social system. He describes that compatibility is one of the five characteristics that influence consumers' adoption of a new technology in the diffusion of innovation theory (Rogers, 1995). He defines compatibility as the existence of consistency between a new technology and an individual's experiences, values and beliefs, and current needs (Rogers, 1995). In the field of information systems, Taylor and Todd (1995) applied this concept to examine the use of computing resource centers among business school students, and found a positive relationship between compatibility and attitude toward the use of computing resource centers. Similarly in the online shopping context, compatibility has been found to have a positive impact on consumer attitudes toward using a virtual store (Chen et al., 2002). Scholars applied this compatibility concept directly to the specific mobile commerce situations to predict its impact on behavioral intention (Mallata et al., 2009; Wu \& Wang, 2005), whereas other scholars have applied it by investigating its impact on attitudes toward the general technology and the virtual store (Chen et al., 2002; Hung et al., 2006; Taylor \& Todd, 1995). Chen et al. (2009) investigated the acceptance and diffusion of the use of the innovative smart phones and found that compatibility was one of the key factors influencing the consumer's attitude toward the use of the smart phone. All of the previous research measured the compatibility of the specific context (e.g. a virtual store, mobile ticking service, computing resources center, and government services) as it directly related to attitudes and behavioral intention toward these contexts. However, a majority of the research investigated the effects of compatibility in a specific situation instead of extending it to different situations with the use of the same technology. As mobile technology has been widely accepted as a method of communication, there might be a great possibility to extend this mode of communication to various other contexts. The present study applies the compatibility concept in the mobile technology setting to examine positive effects of the compatibility of mobile use for communication purposes on consumers' attitudes toward mobile shopping. Thus, based on the literature, we propose the following hypothesis:

H1. Compatibility of mobile communication will positively influence users' attitudes toward mobile shopping.

\section{Theory of Reasoned Action (TRA)}

\section{1) Attitude}

Ajzen and Fishbein (1980) postulated that an individual's behavioral intention depends on his or her attitude and subjective norm. According to the TRA, an attitude toward mobile shopping may be an immediate determinant of future intention to use mobile technology for shopping. In an electronic commerce setting, Vijayasarathy (2004) found that consumers' favorable attitudes toward Internet shopping were significantly associated with their intention to shop online. Similarly, Spanish consumers' attitudes toward mobile commerce predicted future shopping behavior via mobile technology (Bingé et al., 2007). Consumers who had positive attitudes toward purchasing goods and services using mobile devices were more willing to adopt mobile technology for shopping (Bingé et al., 2007). Recently, Kim et al. (2009) identified additional evidence for this relationship among attitude, subjective norm, and behavioral intention in the context of mobile application for the fashion industry. Kim et al. (2009) found a positive causal relationship between U.S. young adult consumers' attitudes toward the mobile commerce and their 
behavioral intention regarding mobile commerce in the fashion industry context. Thus, we hypothesize the positive effect of attitude toward mobile shopping on behavioral intention toward mobile shopping:

$\mathrm{H} 2$. Attitude toward mobile shopping will positively influence intention to use mobile shopping.

\section{2) Subjective Norm}

Several empirical studies have pointed out the importance of reference group influences to explain and predict behavioral intentions for technology use (e.g., Bhattacherjee, 2000; Davis, 1989; Kim et al., 2009). For instance, researchers found that subjective norm was an important predictor of the intention to adopt wireless Internet (Lu et al., 2003), e-commerce (Bhattacherjee, 2000), and an interactive television as e-commerce medium (Wu \& Wang, 2005), including the actual usage of Internet messaging (Premkumar et al., 2008). Respondents tended to rely on opinions from prior adopters such as their peers and family in their decision to adopt e-commerce service usage. The mobile service acceptance model proposed by Lu et al. (2003) also asserted that, in some cases, the views of others might influence individuals to adopt wireless Internet through their own mobile phones. Nysveen et al. (2005a) found that normative pressure was an important determinant of consumers' intention to use mobile services. Those who felt more social pressure from peers or superiors regarding using mobile phones exhibited a higher tendency to adopt mobile services, compared to ones who felt less social pressure. This finding is consistent with the theoretical proposition of Davis (1989), who argued that consumers might accept a technology to comply with others who are important to them rather than reacting to their own feelings and beliefs about its use. A recent study by Kim et al. (2009) provides empirical support for the positive relationship between subjective norm and behavioral intention toward mobile commerce. Specifically, the effects of significant others as an interpersonal level on behavioral intention to use a new form of technology received strong support (Kim et al., 2009). However, most of the previous studies focused on outcomes of subjective norm and its impact on behavioral intention to use the technology rather than the possible antecedents of subjective norm in the mobile commerce context.

Mobile usage for communication purposes is interpersonal social behavior among ones' friends, peers, and family. The influences of significant others on one's use of mobile devices for communication purposes also impact the effect on its use for shopping purposes from the perspective of the media dependency theory (BallRokeach \& DeFleur, 1976; Grant et al., 1991). For instance, one's peers' beliefs in terms of mobile usage for communication purposes can be transferred to the subjective norm for mobile use for shopping. This plausible relationship is supported by the previous research explaining the importance of reference group influence regarding adoption of technology (Bhattacherjee, 2000; Kim et al., 2009; Lu et al., 2003; Premkumar et al., 2008; Wu \& Wang, 2005). In the diffusion of innovation theory, Rogers (1995) asserted the influence of interpersonal network on one's adoption of an innovation or a new idea. Although there is no empirical studies examined the relationship of subjective norm with mobile communication and the one with mobile shopping, the previous studies (Bingé et al., 2007; Kim \& Park, 2005) identified two kinds of shifting effects of attitudinal and behavioral intention. It is plausible that consumer's perception of subjective norm regarding the mobile usage for general communication purposes (common activity) could be extended to the mobile usage for shopping purposes, which we framed in our study as the newer activity. Therefore, in the present study, we proposed to examine the effects of subjective norm at the communication level on the same at the shopping level as an antecedent of subjective norm of use of mobile device for shopping purposes. We have generated the following hypotheses to examine the relationships among precursors of mobile shopping intention on the interpersonal level.

H3. Subjective norm with mobile communication will positively influence users' subjective norm for mobile shopping.

H4. Subjective norm for mobile shopping will positively influence intention to use mobile shopping.

\section{Media Influences}

In a discussion of the diffusion of innovation theory, 
Rogers (1995) stressed the imperativeness of mass media effects on the adoption of an innovation. In terms of new technology usage, the roles of mass media as an external level have been valuable in influencing one's acceptance of electronic brokerage context (Bhattacherjee, 2000). He suggested that dissemination through popular press about a new technology was valuable in increasing consumers' awareness in the earlier stage of the diffusion process of a new idea or technology (Bhattacherjee, 2000). Shao (1999) found that the media influenced the early adoption of the technology over a two-year period. The TRA (Ajzen $\&$ Fishbein, 1980) does not integrate any external variables to explain behavior intention. While compatibility is on an internal level and subjective norm is on an interpersonal level, media influences, which we integrate in the present study, is considered one of the influential factors at the external level that predict consumers' intentions toward mobile shopping. To our best knowledge, there has been little research effort about the possible impact of media influences on consumers' adoption of new technology considering both communication and shopping levels. By extending the logic to develop Hypothesis 3, we also proposed that media influences toward the mobile use for communication purposes can be shifted toward those regarding mobile use for the shopping purposes. The latter is viewed as more advanced function using the mobile device and has been the focus of the mobile industry to promote their services and newer versions of mobile devices. In addition, the fashion industry also adopted the mobile technology to push its innovative retail medium to penetrate the market segment of fashion innovators as well as the tech-savvy consumers. Thus, we anticipated that individuals with higher levels of media influence perceptions regarding mobile device use for communication purposes will be more likely to perceive media influences regarding mobile device usage for the commerce functions positively. Therefore, in the present study, we aim to fill this void in the literature and propose the media influences of mobile shopping, as an external factor to expand the TRA. We argue that media influences will affect the consumers' behavioral intention regarding the usage of mobile devices for shopping. In addition, integrating the concept of media depen- dency theory by examining its shifting roles from communication to shopping levels, media influence on the communication level will also positively predict media influences on the shopping level. Thus, we hypothesize:

H5. Media influences on mobile communication will positively impact media influences on mobile shopping.

H6. Media influences on mobile shopping will positively impact the intention to use mobile shopping.

\section{Methods}

\section{Data Gathering and Sample}

An online self-administered survey was designed to collect the data for the present study. The population of the study was the multichannel shoppers. In total, ten thousand e-mail invitations were sent out to a national sample purchased from an independent marketing research company. The sample was randomly selected from panel members of the marketing research company and consisted of current mobile phone users with a minimum age of 19. We followed Dillman's (2007) suggestions for online survey follow-ups. About four days later, a week after invitation e-mail letters were sent out, the second and the third reminder e-mails were sent to the people who had not responded within a timely manner to the survey. A total of 1,602 responses were obtained resulting in a response rate of $16.02 \%$. A screening question was used to identify multichannel shoppers. We targeted multichannel shoppers who had experiences with purchasing any products from both online and physical stores operated by one multichannel retailer. The item included as screening question was, "have you had purchased any products from both physical and online stores operated by one multichannel retailer?" Those who answered "no" were directed to the disqualification page thanking their willingness to participate the study and explaining that they were not appropriate panel for the present study. As a sample of the present study, those who only answered "yes" were included. They were also asked to provide the name of the multichannel retailer with which they shopped, and to complete the remaining questionnaire 
based on the retailer they answered. Of 576 complete responses from multichannel shoppers, we obtained a usable data of 524 for further data analyses after screening for incomplete responses. Regarding mobile usage for communication purposes, all participants reported their usage of mobile devices for calling others; slightly more than two third of them $(69.3 \%)$ had communicated with others via SMS; about half (51\%) had experienced sending or receiving MMS.

We examined non-response bias by comparing the responses of early and late respondents as it is suggested that there were similarities between late respondents and non-respondents (Armstrong \& Overton,
1977). We compared all the research constructs used in the proposed framework as well as demographic variables using $t$-test and/or $\chi^{2}$ test to detect if there was non-response bias. There were no significant differences in any of the variables, so we carefully conclude that non-response bias was not suspected: $t$-values for research variables ranging from .625 to $1.920(p>.05)$, and $\chi^{2}$ values for demographic variables ranging from 1.950 to $11.189(p>.05)$.

\section{Instrument Development and Data Analysis}

All items used in the present study are exhibited in

Table 1.The results of CFA analysis for the measurement model

\begin{tabular}{|c|c|c|c|c|c|}
\hline $\begin{array}{l}\text { Dimensions } \\
\text { of factors }\end{array}$ & Items & $\begin{array}{c}\text { Standardized } \\
\text { Factor } \\
\text { loadings } \\
\end{array}$ & AVE & $\mathrm{CR}$ & $\begin{array}{c}\text { Cronbach's } \\
\text { alpha }\end{array}$ \\
\hline Comp_comm & $\begin{array}{l}\text { Using mobile devices fit well with my lifestyle. } \\
\text { Using mobile devices fit well with my communication needs. } \\
\text { Using mobile devices fit well with my daily activities }\end{array}$ & $\begin{array}{l}.95^{*} \\
.88(23.49) \\
.91(24.94) \\
\end{array}$ & .84 & .97 & .95 \\
\hline SN_comm & $\begin{array}{l}\text { People who influence my behavior encourage me to use mobile devices. } \\
\text { People who are important to me suggest me to communicate using mobile } \\
\text { devices. } \\
\text { People who I value recommend me to use mobile devices to be in } \\
\text { touch with them. }\end{array}$ & $\begin{array}{l}.86^{*} \\
.81(22.52) \\
.84(21.02)\end{array}$ & .70 & .93 & .92 \\
\hline Media_comm & $\begin{array}{l}\text { I have read or seen media reports saying that mobile devices provide a } \\
\text { good way of communicating with others. } \\
\text { The popular press adopts a positive view towards using mobile devices. } \\
\text { Mass media have influenced me to use mobile devices for any purpose. }\end{array}$ & $\begin{array}{l}.62 * \\
.57(10.90) \\
.70(12.78)\end{array}$ & .40 & .76 & .71 \\
\hline Att_shop & $\begin{array}{l}\text { I would feel that using mobile shopping is a good idea. } \\
\text { I would feel that using mobile shopping is a wise idea. } \\
\text { I would like to use mobile shopping. }\end{array}$ & $\begin{array}{l}.78^{*} \\
.82(29.29) \\
.95(23.97) \\
\end{array}$ & .73 & .94 & .93 \\
\hline SN_shop & $\begin{array}{l}\text { People who influence my behavior would encourage me to purchase } \\
\text { goods/services via mobile devices. } \\
\text { People who are important to me would suggest me to search for prod- } \\
\text { uct/service information using mobile devices. } \\
\text { People who I value would recommend me to use mobile devices for } \\
\text { shopping. }\end{array}$ & $\begin{array}{l}.90 * \\
.96(39.56) \\
.95(38.86)\end{array}$ & .88 & .98 & .96 \\
\hline Media_shop & $\begin{array}{l}\text { I have read or seen news reports saying that mobile shopping provides } \\
\text { a good way of buying products. } \\
\text { The popular press adopts a positive view towards mobile shopping. } \\
\text { Mass media evoked me to think of using/adopting mobile devices for } \\
\text { shopping. }\end{array}$ & $\begin{array}{l}.77 * \\
.68(19.25) \\
.82(19.24)\end{array}$ & .58 & .88 & .85 \\
\hline Intention & $\begin{array}{l}\text { I would intend to purchase products/services through a mobile device. } \\
\text { I would recommend others to shop through a mobile device. } \\
\text { I would intend to search product/service information through a mobile } \\
\text { device. }\end{array}$ & $\begin{array}{l}.93^{*} \\
.89(38.68) \\
.91(33.21)\end{array}$ & .83 & .97 & .94 \\
\hline
\end{tabular}

AVE: Average variance extracted; CR: Composite reliability, Comp comm: compatibility of mobile communication, $\mathrm{SN}$ comm: subjective norm for mobile communication, Media_comm: media influences for mobile communication, Att_shop: attitudes toward mobile shopping, SN shop: subjective norm for mobile shopping, Media shop: media influence on mobile shopping, Intention: Intention to use mobile shopping 
the $<$ Table $1>$. We used a five-point Likert scale ranging from "strongly disagree" (1) to "strongly agree" (5) to measure the research constructs utilized in the study. To assess compatibility with mobile communication, we modified three items developed by Chen et al. (2002). To measure attitudes toward mobile shopping, subjective norm for mobile communication, and subjective norm for mobile shopping, three items for each construct were modified which Taylor and Todd (1995) generated based on the concept of Ajzen (1991). Three items from Bhattacherjee (2000) were modified to assess media influences on mobile communication and media influences on mobile shopping, respectively. To assess intention to use mobile shopping, we modified three items from Wakefield and Baker (1998) and one time was developed by the authors. To analyze the sample characteristics and test internal validity of research instruments, SPSS 18.0 was used. We utilized LISREL 8.72 with a maximum-likelihood estimation procedure, to test the research hypotheses and proposed model.

\section{Results}

\section{Sample Characteristics}

The average age of the respondents was about 51 years old. Males comprised $41.5 \%$ of the sample, and females made up $58.5 \%$. Approximately $60 \%$ of respondents were married, and nearly $60 \%$ of the participants had some college education or college degree. Another $24 \%$ of participants had post-baccalaureate education. The majority were White or European American (85\%), followed by Black or African American (5.2\%), Latino or Hispanic American (3.8\%), and Asian American (2.3\%). The respondents indicated that they were employed in many different occupations: $20.5 \%$ had jobs related to professional, technical, and related occupations, and about $13.7 \%$ had jobs related to executive, administrative, and managerial occupations, or administrative support occupations. Nearly $60 \%$ of the participants reported more than $\$ 50,000$ as their annual household income. About one-half of the respondents lived in a suburban area and one-quarter lived in metropolitan or urban areas. Respondents to the study repre- sented 47 states with the exceptions of South Dakota, Vermont, and Wyoming.

\section{Measurement Model}

The proposed model included twenty-one observed items measuring seven latent constructs: Compatibility with mobile communication, subjective norm for mobile communication, media influences on mobile communication, attitude toward mobile shopping, subjective norm for mobile shopping, media influences on mobile shopping, and intention to use mobile shopping. <Table $1>$ presents the results of the measurement model analysis, including standardized factor loadings, $t$-values, average variance extracted (AVE), composite reliability scores, and Cronbach's alpha (Cronbach \& Meehl, 1955) values for each construct. Confirmatory factor analysis of the measurement model for multi-item scales showed that factor loadings of indicators for each construct were statistically significant and sufficiently high for structural model testing (Fornell \& Larcker, 1981). Individual reliability was assessed by examining the loadings of the items with their respective construct. The estimated loadings for all the items in each construct were found to be significant with $t$-values between 10.90 and 39.56. The Cronbach's alphas (Cronbach \& Meehl, 1955) for each of the scales were high (ranged 0.71 to 0.96 ), indicating good intemal validity of research constructs.

In addition, construct reliability was assessed using the composite reliability for all constructs calculated as Fornell and Larcker (1981) suggested. As <Table 1> shows, the values for composite reliability for all the constructs in the study ranged from 0.76 to 0.98 , which were above the 0.70 considered to be the threshold recommended by Hair et al. (1998). Convergent validity was assessed by the AVE, which should be at least .50 (Fornell \& Larcker, 1981). The AVE values of the model constructs ranged from 0.40 to 0.88 , which were higher than the acceptable measurement structure of the construct except media influences on mobile communication variable, indicating adequate convergent validity amongst the model constructs. Discriminant validity was also assessed by the AVE values which should be greater than the squared correlation of that 
Table 2. Interconstruct correlations

\begin{tabular}{|c|c|c|c|c|c|c|c|}
\hline & 1 & 2 & 3 & 4 & 5 & 6 & 7 \\
\hline Comp_comm & .91 & & & & & & \\
\hline SN_comm & .44 & .81 & & & & & \\
\hline Media_comm & .57 & .60 & .52 & & & & \\
\hline Att_shop & .35 & .15 & .20 & .83 & & & \\
\hline SN_shop & .23 & .53 & .48 & .60 & .93 & & \\
\hline Media_shop & .26 & .40 & .45 & .76 & .84 & .70 & \\
\hline Intention & .30 & .30 & .31 & .80 & .75 & .62 & .90 \\
\hline Mean & 3.64 & 3.00 & 3.22 & 2.84 & 2.41 & 2.69 & 2.45 \\
\hline$S D$ & 1.05 & 1.04 & .76 & 1.02 & 1.01 & .88 & 1.05 \\
\hline
\end{tabular}

Values shown on the diagonal in bold are the square root of the average variance extracted for each construct.

construct to other constructs (Table 2). All latent constructs satisfied all three conditions. Therefore, each construct had adequate reliability as well as convergent and discriminant validities.

\section{Structural Model}

The proposed conceptual model, $<$ Fig. $1>$ was tested by employing a structural equation modeling technique using the LISREL 8.72. The model was examined in terms of model goodness-of-fit, overall explanatory powers, and hypothesized causal relationships among the model constructs. The results of structural equation modeling analysis for the proposed model revealed a $\chi^{2}$ of 415.20 with degree of freedom of $167\left(\chi^{2} / d f\right.$ of 2.49 ; $p<.001$ ), goodness-of-fit index (GFI) of .93, adjusted goodness-of-fit index (AGFI) of .90, comparative fit index (CFI) of .99, normed fit index (NFI) of .98, relative fit index (RFI) of .98, incremental fit index (IFI) of .99 , and root mean square residual of .053 . Generally,

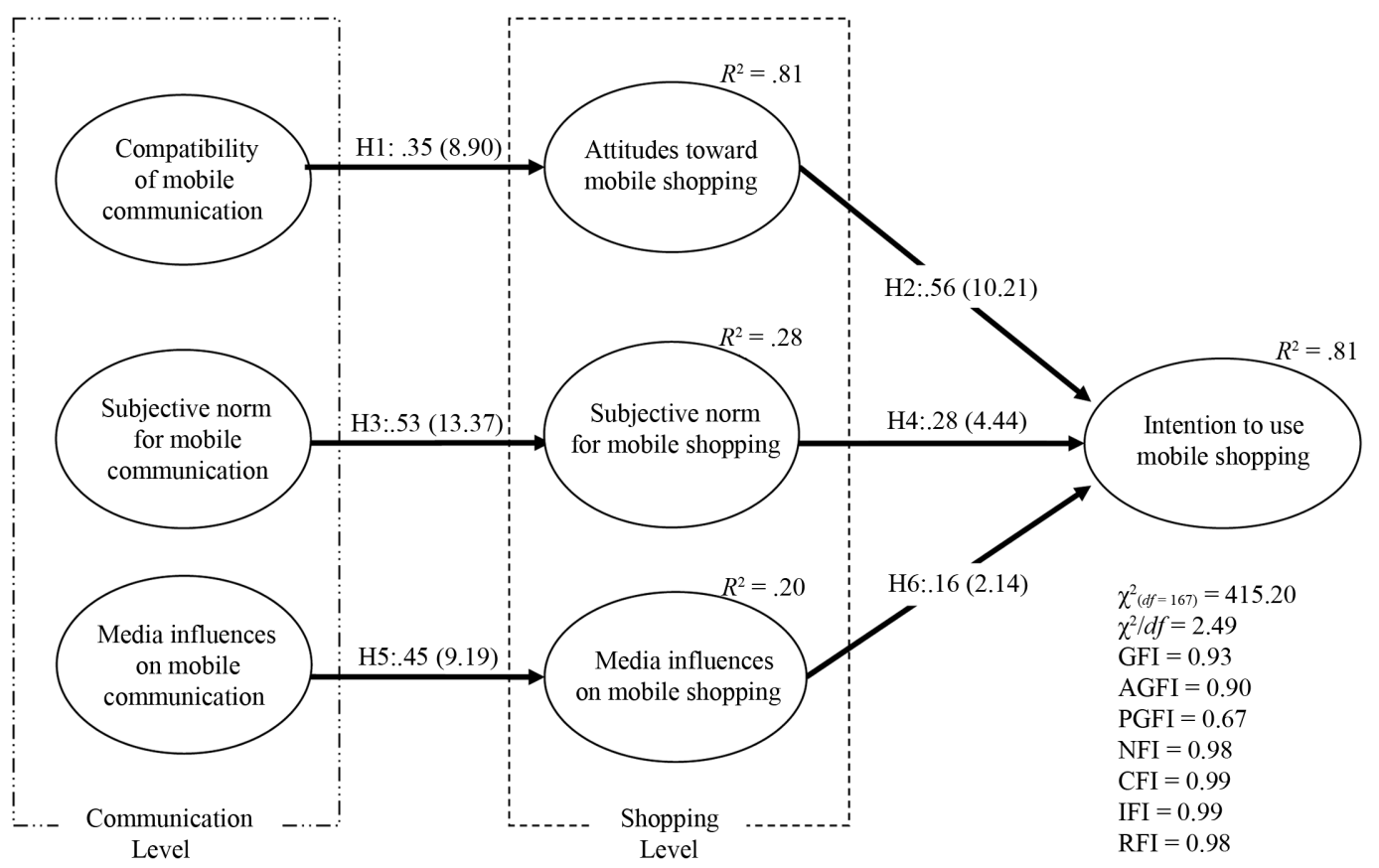

Fig. 1. A mobile channel extension model. 
fit statistics greater than or equal to .90 for GFI, NFI, RFI, CFI, and IFI are considered to indicate a good model fit (Bagozzi \& Yi, 1998; Hair et al., 1998). Also, acceptable ranges for root mean square error of approximation (RMSEA) values are .05 to .08 (Hair et al., 1998). Therefore, the RMSEA value of 0.053 suggests that the model fit was also appropriate.

The overall explanatory power of the model was estimated by examining the $R^{2}$ values for the four endogenous constructs in the proposed model. Compatibility to mobile communication explained $12 \%$ of total variance of attitudes toward mobile shopping. Subjective norm for mobile communication explained $28 \%$ of total variance of subjective norm for mobile shopping. Media influences on mobile communication explained $20 \%$ of total variance of media influences on mobile shopping. In addition, $81 \%$ of the total variance of behavior intention regarding mobile shopping was explained by three preceding endogenous variables in the model, attitudes toward, subjective norm regarding, and media influences on mobile shopping.

All six hypotheses in the present study were statistically supported $(p<.05)$. $<$ Fig. $1>$ presents results of the causal model testing. Compatibility with mobile communication had a positive relationship to attitudes toward mobile shopping $(\mathrm{H} 1: \beta=.35, t=8.90)$, and attitudes toward mobile shopping had a significant direct effect on behavioral intention to use mobile shopping $(\mathrm{H} 2: \beta=.56, t=10.21)$. As we hypothesized, subjective norm for mobile communication exhibited significant positive effects on subjective norm for mobile shopping $(\mathrm{H} 3: \beta=.53, t=13.37)$ and subjective norm for mobile shopping subsequently had a positive, direct influence on behavioral intention to use mobile shopping ( $\mathrm{H} 4: \beta=$ $.28, t=4.44$ ). As we proposed, media influences on mobile communication positively affected media effects on mobile shopping ( $\mathrm{H} 5: \beta=.45, t=9.19)$, and media influences on mobile shopping had a significant positive effect on behavioral intention to use mobile shopping (H6: $\beta=.16, t=2.14$ ).

\section{Discussion}

The present study approached consumers' possible future adoption of mobile shopping by investigating behavioral intention regarding mobile shopping and possible three antecedents from three different levels of evaluation of the mobile devices: individual/internal level (H1: a positive relationship between compatibility and attitude), interpersonal level (H3: a linkage between subjective norm for mobile communication and subjective norm for mobile shopping), and external level (H5: linkages between media influences on mobile communication as well as media influences on mobile shopping). In turn, all three dependent variables mentioned above explained the consumer's behavioral intention regarding the use of mobile devices for shopping. As we conceptualized, there were in fact positive relationships between individual consumers' cognitive evaluations of mobile devices for communication purposesattitude, subjective norm, and media influences- and their evaluation of mobile use for shopping. In mobile marketing literature, numerous studies focus on the technology acceptance model and/or its precursors to explain the phenomenon of adoption or use of mobile devices in regards to marketing efforts (Bruner \& Kumar, 2005; Kulviwat et al., 2007; Nysveen et al., 2005b) and mobile shopping for merchandise (Kim et al., 2009; Ko et al., 2010). This study examined a potential channel extension of mobile among multichannel shoppers in a multichannel retailing environment as Lee and Lee (2010) identified that those who use various Internet services had strong intentions to use the same services via mobile. The present study was the first attempt to investigate the attitude, subjective norm, and media influences shifts from communication level of mobile usage to shopping level of that by integrating the TRA and diffusion of innovation theory on the conceptual ground base of media dependency theory. The findings of the study show that the consumer's activities can shift from mobile communication to mobile shopping as we proposed. Compatibility, subjective norm, and media influences at a communication level were examined as antecedents of a shopping level via mobile devices. This suggests that our proposition based on media dependency theory received empirical support in both mobile communication and shopping contexts.

The results of the study added empirical support regarding the effects of compatibility of a technology on the attitude toward using the technology to the previous 
literature in information system management (e.g., Chen et al., 2002; Hung et al., 2006; Taylor \& Todd, 1995). In the present study, we found the positive and significant role of compatibility of using mobile device for communication on attitudes toward use of mobile device for shopping). Furthermore, this finding is in line with previous research that investigated mobile technology (Chen et al., 2009), extending its effects of mobile device usage for communication on consumer's attitude toward using mobile devices in a shopping context. The respondents, who reported that the use of mobile devices for communication purposes is compatible with their lifestyles, exhibited a positive attitude toward mobile shopping. In addition, participants who reported that they are influenced by significant others' opinions in the use of mobile devices for communication purposes exhibited a higher level of that influence on the use of mobile devices for a shopping purpose. As an additional construct to TRA in our framework, positive causal relationship from media influences on a communication level to media influences on a shopping level using mobile devices was examined. This finding is parallel to that of previous research (Balabanis \& Reynolds, 2001; Kim \& Park, 2005), that adopted the media dependency theory and found the attitude and/or behavioral intention shift from the common technology/medium use to more advanced technology/medium use. The finding of present study suggests that information delivered by mass media impacts consumers' activities using the mobile devices from communication to shopping purposes. In terms of attitude and behavioral intention relationships, all three mediating variables-attitude toward mobile shopping, subjective norm for mobile shopping, and media influences on mobile shoppingpositively predicted respondents' intentions to use mobile devices for shopping. The results of the study provide the empirical evidence to extend the relationships among the variables in the TRA to the mobile shopping context. This result is parallel to previous mobile commerce research (Bingé et al., 2007; Kim et al., 2009) and e-commerce research (Taylor \& Todd, 1995; Vijayasarathy, 2004) on the positive relationships between attitude and behavioral intention as well as subjective norm and behavioral intention and/or actual behavior. Attitudes toward mobile shop- ping provide the strongest effects on intention to use mobile shopping followed by subjective norm. The findings on the positive influence of subjective norm on behavioral intention are in line with the previous research (Huang et al., 2006; Lu et al., 2003; Premkumar et al., 2008). Moreover, significant causal relationships between media influences on mobile shopping and intention to use mobile shopping suggest the roles of mass media on the adoption and usage of mobile devices for shopping purposes, which confirms the previous findings on electronic commerce (Bhattacherjee, 2000) and new technology (Shao, 1999). Although the relationship was weak compared to the other two variables (attitudes and subjective norm), the findings of the present study suggested the value of the media influences on mobile devices for shopping purposes.

\section{Implications for the Academia}

The findings of the present study provide empirical support to our proposition that communication activities using mobile devices can predict shopping activities using mobile devices. Based on the findings of the study, we assert through the media dependency theory, that mobile devices can be influential sources for individuals, and therefore could be potential venues for shopping. This suggests that mobile devices are influential media for many individuals who find the devices compatible with their lifestyles, and who value significant others' opinions and/or information about the mobile devices presented by other media for many purposes, to extend its possible usage beyond communication purposes. The results of the present study extend the use of media dependency theory in the area of marketing via mobile devices. In addition, the results of the present study extended the TRA in identifying antecedents of attitudes and subjective norm, as well as finding media influences to be an additional construct to explain behavioral intention regarding the mobile shopping context. As mobile shopping is a new concept to consumers, explaining the intention to use mobile shopping concepts from innovation diffusion were integrated to extend the TRA. Originally, the compatibility concept was identified in the diffusion of innovation theory, specifying that consumers are more willing to adopt 
a new idea/technology if it is compatible with their lifestyle, values, and previous experiences (Rogers, 1995). This concept was applied to the present study as well to explain consumer attitude toward mobile shopping if their lifestyle and daily mobile phone activities were compatible with using mobile devices for communication purposes. The results of the present study suggest further attention be paid to the concept of compatibility applied in the study as there was a significant direct effect of compatibility in mobile shopping. This study takes the first step to examine compatibility as an antecedent of attitude and its relationship with intention to use mobile shopping by receiving empirical support that compatibility is one of the important individual characteristics to increase adoption of an innovation (Rogers, 1995). It would be valuable to further consider other consumers' characteristics that influence their innovation adoption behaviors using other concepts identified by Rogers (1995) including relative advantage, complexity, triability, and observability, along with compatibility in the mobile shopping context to explain their effects on attitude as well as intention.

Moreover, subjective norm in the communication level was examined as an antecedent of the subjective norm for the mobile shopping level for which the relationship was positive. The strong effect of subjective norm of mobile communication on that of mobile shopping asserted that subjective norm of mobile communication level was the significant antecedent of that of shopping level. This finding also asserted the importance of interpersonal communication in spreading out a new innovation (Rogers, 1995).

In addition to the attitude and subjective norm constructs in the TRA, this study included a new construct, namely, media influences to examine its effect in the communication level on that in the shopping level, and its impact in shopping level on intention to use mobile shopping. In line with Kim et al.'s (2009) findings, our study found that the media influences on the use of mobile communication positively predicted its effects on the use of mobile shopping, and the latter positively predicted behavioral intention to use mobile shopping. Kim and Park (2005) found this effect to be an attitude shift from using the Internet for communication to shopping purposes, following media dependency the- ory. The findings of the study also suggest that effects of media in mobile device usage for communication purposes was the antecedent of its effects on mobile shopping, and media influences were interpreted as an additional construct to explain behavioral intention to use mobile shopping, together with attitude and subjective norm. Media influences on mobile communication usages had a significant positive relationship on the media influences with mobile shopping usages.

Thus, the present study contributes to extending the TRA by investigating the antecedents of attitudes and subjective norm, and identifying a new construct and media effect, that have a direct and positive impact on the consumer's intention to use mobile shopping with the integration of diffusion of innovation theory. Although Rogers (1995) identified the importance of external factors such as influences of mass media and organization and/or society support in adoptions of innovations, the TRA did not capture effects of external factors on behavioral intentions. The study highlights the role of an external factor (media effect) in explaining intention to use mobile devices for shopping purposes. Not only would individual attitudes and significant others' opinions predict one's behavioral intention, but also information addressed in the press and mass media about new innovations are important factors that influence one's behavioral intention. Especially, as mobile shopping is an emerging concept for consumers to adopt, exposing this concept to consumers by highlighting and conveying the practicality of it via various types of media would help the mobile industry promote its transactional functions to the mobile users. Thus, the findings of the study integrating media influence of mobile technology in communication and shopping level as external variables on intention to use mobile shopping, provide significant theoretical contributions in explaining consumer acceptance in regards to the new technology.

\section{Implications for the Industry}

Based on the results of the present study, we suggest that the usage of mobile devices, for communication purposes, can positively predict usages of mobile devices for shopping. We also suggest that those consumers 
who feel that using mobile devices for communication purposes fit with their lifestyles and activities would be highly likely to use mobile shopping. Mobile shopping marketers should pay attention to consumers' compatibility issues to successfully persuade them to adopt mobile shopping. Although consumers currently do not use mobile devices for functions other than communication purposes, heavy users of mobile phones or PDAs would be a potential market for marketers to increase mobile shopping business, as there was a significant indirect effect of compatibility on intention to use mobile shopping in the study. As noted by Rogers (1995), mass media channels are more effective in creating knowledge of innovations. Since it is in an early adoption phase, it is important for the mobile commerce industry to educate and inform customers to promote the various ways of using mobile devices by using multi-media to spread the word to key innovators as well as early adopters.

Roger (1995) also stressed that interpersonal channels or reference groups are more effective in forming and shifting attitudes toward a new idea (in our case, use of mobile device for shopping) and in turn, influencing the individual's the decision to adopt or reject the new idea. The findings of the present study confirm the assertions made by Rogers (1995). The fashion retail industry may embrace the young adult consumers as innovators influencing the consumers within its generation and/or across other generations to form a positive attitude toward the adoption of the mobile usage for commerce purposes.

The results of the study provide the effects of significant others in the use of mobile technology for shopping purposes on behavioral intention to use mobile shopping. Again, strong influences of subjective norms in the communication level positively predict its effects on a shopping level via mobile devices. This finding suggests that consumers, who feel that people they value use a mobile device for communication, would be more likely to use a mobile device for shopping purposes for the same reason. Furthermore, these results indicate that there is a subjective norm, for mobile shopping, with a significant effect on behavioral intention to use mobile shopping. Consumers who might be easily influenced by peers, such as young consumers, would be the optimal segment for marketing efforts regarding mobile shopping. Therefore, attention is needed to consider the interpersonal influences of consumers and their significant others. To entice a consumer group to use mobile shopping, finding a reference group and/ or significant others from the target market would be valuable for practitioners, since the findings of this study strongly identify the effects of subjective norm in the mobile shopping context. Furthermore, this study identified the significant media influences as one of the factors in predicting behavioral intentions regarding mobile shopping. Even though communication through mobile devices is ubiquitous, the concept of shopping through mobile devices is still new to U.S. consumers. It would be beneficial that practitioners educate consumers and provide information related to the benefits and opportunities of mobile shopping using various media. Reporting continuous articles, news reports, press, and advertisements from the radio, TV, and the Internet about the potentials of mobile shopping, or even new ways to use mobile devices for various services except communication, would be a positive way to embrace potential consumers and introduce them to the benefits of mobile shopping.

\section{Contribution, Limitation, and Future Research}

The present study contributes to explaining the shift in consumer attitudes of mobile technology usage from communicational to transactional purposes. It further provides empirical support for its shifting roles in various levels including individual, interpersonal, and external levels. Therefore, the study provides strong evidence of the roles of media effects on consumer acceptance of technology for a newer shopping mode. The findings provide potential theoretical development for academia, as well as suggest possible solutions to the mobile industry regarding how to increase consumer awareness about mobile shopping through mass media marketing communication.

This study is not without limitations. We screened samples to ensure participants to be multichannel shoppers who had purchased goods from the physical and the online retailer operated by same multichannel re- 
tailer. However, we did not screen based on their accessibility to mobile devices that allow shopping, because at the time of data collection, mobile shopping was still very new to the general population. Consumers, who own mobile devices such as smart phones or iphones, may have varying attitudes, as well as aptitudes, toward these devices allowing the mobile shopping experience. Ownership of smart phones can be used as a moderator in further investigation of the consumer adoption and/or usage of mobile shopping. We also intended to investigate the possible antecedents of future adoption of mobile shopping. The future study may target a sample that has mobile shopping experience to examine the in-depth mechanism of the motivations behind the use of mobile devices for shopping for physical goods and/or services. In addition, the present study examined the proposed conceptual framework in a general product-free context without specifying a particular product or service. A future study conducted for certain product categories might provide different findings, so further studies would be advantageous in applying the model from the present study to specific categories of merchandise and specific user situations. In the model, media influences on mobile communication did not meet the criteria to meet discriminant validity although other constructs exceed the criteria. It is suggested that future study replicate the present study to further clarify and refine the measures in this construct.

In the present study we aimed to incorporate new concepts to expand the theory of reasoned action. The compatibility of mobile use for communication purposes is the concept we adopted from the diffusion of innovation theory in order to more fully capture the mobile usage for communication purposes and to predict the consumer's behavioral intention regarding mobile shopping. Although we conceptually proposed and found empirical support for the positive linkage between the compatibility and attitude toward mobile shopping, a future study to replicate this assertion may be useful to solidify our conceptualization. This study examined the effects of subjective norm valued by respondents. Consumers in specific market segments might have different significant others and different reference groups, so it would be useful for future studies to pay precise attention to the types of subjective norm, which different significant others consumers value, and analyze their effects on actual decision-making processes with regard to mobile shopping contexts. Finally, although the present study examined media influences on communication and shopping levels, we did not examine any particular type of media and an individual's dependency on the type of media, nor their effects on behavioral intention to use mobile shopping. As there are various types of mass media that each target market may value differently, further studies are needed to investigate different types of media and their influences on behavioral intention to use mobile shopping. Moreover, considering the media effects, it would be rewarding for academia to examine consumer adoption and user intention for other forms of technology and/or services.

\section{References}

Ajzen, I. (1991). Theory of planned behavior. Organizational Behavior and Human Decision Processes, 50, 179-211.

Ajzen, I., \& Fishbein, M. (1980).Understanding attitudes and predicting social behavior. Englewood Cliff, NJ: Prentice-Hall.

Armstrong, J. S., \& Overton, T. S. (1977). Estimation nonresponse bias in mail surveys. Journal of Marketing Research, 14(3), 396-402.

Bagozzi, R. P., \& Yi, Y. (1988). On the evaluation of structural equation models. Journal of the Academy of Marketing Science, 16(1), 74-94.

Balabanis, G., \& Reynolds, N. L. (2001). Consumer attitudes towards multichannel retailer's websites: The role of involvement, brand attitude, internet knowledge and visit duration. Journal of Business Strategies, 18(2), 105129.

Ball-Rokeach, S. J., \& DeFleur, M. L. (1976). A dependency model of mass media effects. Communication Research, 3(1), 3-21.

Bingé, E., Ruiz, C., \& Sanz, S. (2007). Key drivers of mobile commerce adoption: An exploratory study of Spanish mobile users. Journal of Theoretical and Applied Electronic Commerce Research, 2(2), 48-60.

Bhattacherjee, A. (2000). Acceptance of e-commerce services: The case of electronic brokerages. IEEE Transactions on Systems, Man, and Cybernetics-Part A: Systems and Humans, 30(4), 411-420.

Bruner II, G, C., \& Kumar, A. (2005). Explaining consumer acceptance of handheld Internet devices. Journal of Business Research, 58(5), 553-558.

Chen, L. D., Gillenson, M. L., \& Sherrell, D. L. (2002). 
Enticing online consumers: An extended technology acceptance perspective. Information and Management, 39(8), 705-719.

Chen, J. V., Yen, D. C., \& Chen, K. (2009). The acceptance and diffusion of the innovative smart phone use: A case study of a delivery service company in logistics. Information and Management, 46(4), 241-248.

Cheong, J. H., \& Park, M. C. (2005). Mobile internet acceptance in Korea. Internet Research: Electronic Networking Applications and Policy, 15(2), 125-140.

Constantiou, I. D., Damsgaard, J., \& Knutsen, L. (2006). Exploring perceptions and use of mobile services: User differences in an advancing market. International Journal of Mobile Communications, 4(3), 231-247.

Cronbach, L. J., \& Meehl, P. E. (1955). Construct validity in psychological tests. Psychology Bulletin, 52, 281-302.

Davis, F. D. (1989). Perceived usefulness, perceived ease of use and user acceptance of information technology. MIS Quarterly, 13(3), 319-340.

Dillman, D. A. (2007). Mail and internet surveys: The tailored design method (2nd ed.). New York: John Wiley and Sons.

Frattaroli, M. (2009). Compete blog: Cross-channel retailwhat are online customers doing today? RetailWire. Retrieved April 3, 2010, from http://www.retailwire.com/ Discussions/Sngl Discussion.cfm/13922

Fornell, C., \& Larcker D. F. (1981). Evaluating structural equation models with unobservable variables and measurement models. Journal of Marketing Research, 18(1), 39-50.

Grant, A. E., Guthrie, K. K., \& Ball-Rokeach, S. J. (1991). Television shopping: A media system dependency perspective. Communication Research, 18(6), 773-798.

Hair, J. F., Tatham, R. L., Anderson R. E., \& Black, W. (1998). Multivariate data analysis. Upper Saddle River, NJ: Prentice-Hall

Hung, S. Y., Chang, C. M., \& Yu, T. J. (2006). Determinants of user acceptance of the e-government services: The case of online tax filing and payment system. Government Information Quarterly, 23(1), 97-122.

IANS. (2010, February 16). Five billion people to use cell phones in 2010: UN. Thaindian News. Retrieved April 1, 2011, from http://www.thaindian.com/newsportal/scitech/five-billion-people-to-use-cell-phones-in-2010-un 100320649.html

Kim, J. H., Ma, Y. J., \& Park, J. H. (2009). Are U. S. consumers ready to adopt mobile technology for fashion goods? An integrated theoretical approach. Journal of Fashion Marketing and Management, 13(2), 215-230.

Kim, J. H., \& Park, J. H. (2005). A consumer shopping channel extension model: Attitude shift toward the online retailer. Journal of Fashion Marketing and Management, 9(1), 106-121.
Ko, E. J., Kim, E. Y., \& Lee, E. K. (2009). Modeling consumer adoption of mobile shopping for fashion products in Korea. Psychology and Marketing, 26(7), 669687.

Kulviwat, S., Bruner, G. C. II, Kumar, A., Nasco, S. A., \& Clark, T. (2007). Toward a unified theory of consumer acceptance of technology. Psychology and Marketing, 24(12), 1067-1092.

Lee, H. H., \& Kim, J. H. (2010). Investigating dimensionality of multichannel retailer's cross-channel integration practices and effectiveness: Shopping orientation and loyalty intention Journal of Marketing Channels, 17(4), 281-312.

Lee, H. H., \& Lee, S. E. (2007). Mobile commerce: An analysis of key success factors. Journal of Shopping Center Research, 14(2), 29-62.

Lee, H. H., \& Lee, S. E. (2010). Internet vs. mobile services: Comparisons of gender and ethnicity. Journal of Research in Interactive Marketing, 4(4), 346-375.

Li, W., \& McQueen, R. J. (2008). Barriers to mobile commerce adoption: An analysis framework for a countrylevel perspective. International Journal of Mobile Communication, 6(2), 231-257.

Lu, J., Yu, C. S., Liu, C., \& Yao, J. E. (2003). Technology acceptance model for wireless Internet. Internet Research: Electronic Networking Applications and Policy, 13(3), 206-222.

Mallata, N., Rossia, M., Tuunainen, V. K., \& Öörni, A. (2009). The impact of use context on mobile services acceptance: The case of mobile ticketing. Information and Managementm, 46(3), 190-195.

Moorman, J. (2009). Industry surveys: Telecommunications, wireless. New York: Standard \& Poor's Industry surveys.

Mort, G. S., \& Drennan, J. (2002). Mobile digital technology: Emerging issues for marketing. Journal of Database Marketing, 10(1), 9-23.

Murphy, S. (2007). Getting iReady. Chain Store Age, 83(8), 84.

Nysveen, H., Pedersen, P. E., \& Thorbjørnsen, H. (2005a). Intentions to use mobile services: Antecedents and crossservice comparisons. Journal of the Academy of Marketing Science, 33(3), 330-346.

Nysveen, H., Pedersen, P. E., \& Thorbjørnsen, H. (2005b). Explaining intention to use mobile chat services: Moderating effects of gender. Journal of Consumer Marketing, 22(5), 247-256.

Pentina, I., \& Hasty, R. W. (2009). Effects of multichannel coordination and e-commerce outsourcing on online retail performance. Journal of Marketing Channels, 16(4), 359-374.

Premkumar, G., Ramamurthy, K., \& Liu, H. N. (2008). Internet messaging: An examination of the impact of attitudinal, 
normative, and control belief systems. Information and Management, 45(7), 451-457.

Rangaswamy, A., \& Van Bruggen, G. H. (2005). Opportunities and challenges in multichannel marketing: An introduction to the special issue. Journal of Interactive Marketing, 19(2), 5-11.

Rogers, E. M. (1995). Diffusion of Innovations (4 $4^{\text {th }}$ ed.). New York, NY: Free Press.

Shankar, V., \& Winer, R. S. (2005). Interactive marketing goes multichannel. Journal of Interactive Marketing, 19(2), 2-3.

Shao, Y. P. (1999). Expert systems diffusion in British banking: Diffusion models and media factor. Information and Management, 35(1), 1-8.

Skumanich, S. A., \& Kintsfather, D. P. (1998). Individual media dependency relations within television shopping programming: A causal model reviewed and revised. Communication Research, 25(2), 200-219.

Tsang, M. M., Ho, S. C., \& Liang, T. P. (2004). Consumer attitudes toward mobile advertising: An empirical study. International Journal of Electronic Commerce, 8(3), $65-78$.
Taylor, S., \& Todd, P. A. (1995). Understanding information technology usage: A test of competing models. Information Systems Research, 6(2), 144-176.

Vijayasarathy, L. R. (2004). Predicting consumer intentions to use on-line shopping: The case for an augmented technology acceptance model. Information and Management, 41(6), 747-762.

Vollmer, C. (2008). Always on: Advertising, marketing and media in an era of consumer control. New York: McGrawHill.

Wakefield, K. L., \& Baker, J. (1998). Excitement at the mall: Determinants and effects on shopping response. Journal of Retailing, 74(4), 515-539.

Wei, R., Xiaoming, H., \& Pan, J. (2010). Examining user behavioral response to SMS ads: Implications for the evolution of the mobile phone as a bona-fide medium. Telematics and Informatics, 27(1), 32-41.

Wu, J. H., \& Wang, S. C. (2005). What drives mobile commerce? An empirical evaluation of the revised technology acceptance model. Information and Management, 42(5), 719-729. 